\title{
The Roles of Aesthetics and Information Quality on Continued Use of Digital Library (CUDL) by Malaysian Postgraduate Students
}

\section{Abd Latif Abdul Rahman \& Shahruhaida Adayu Mohd Paili}

To Link this Article: http://dx.doi.org/10.6007/IJARBSS/v11-i12/11815 DOI:10.6007/IJARBSS/v11-i12/11815

Received: 09 October 2021, Revised: 13 November 2021, Accepted: 27 November 2021

Published Online: 17 December 2021

In-Text Citation: (Rahman \& Paili, 2021)

To Cite this Article: Rahman, A. L. A., \& Paili, S. A. M. (2021). The Roles of Aesthetics and Information Quality on Continued Use of Digital Library (CUDL) by Malaysian Postgraduate Students. International Journal of Academic Research in Business and Social Sciences, 11(12), 723-737.

Copyright: (c) 2021 The Author(s)

Published by Human Resource Management Academic Research Society (www.hrmars.com) This article is published under the Creative Commons Attribution (CC BY 4.0) license. Anyone may reproduce, distribute, translate and create derivative works of this article (for both commercial and non0-commercial purposes), subject to full attribution to the original publication and authors. The full terms of this license may be seen at: http://creativecommons.org/licences/by/4.0/legalcode

Vol. 11, No. 12, 2021, Pg. 723 - 737

Full Terms \& Conditions of access and use can be found at http://hrmars.com/index.php/pages/detail/publication-ethics 


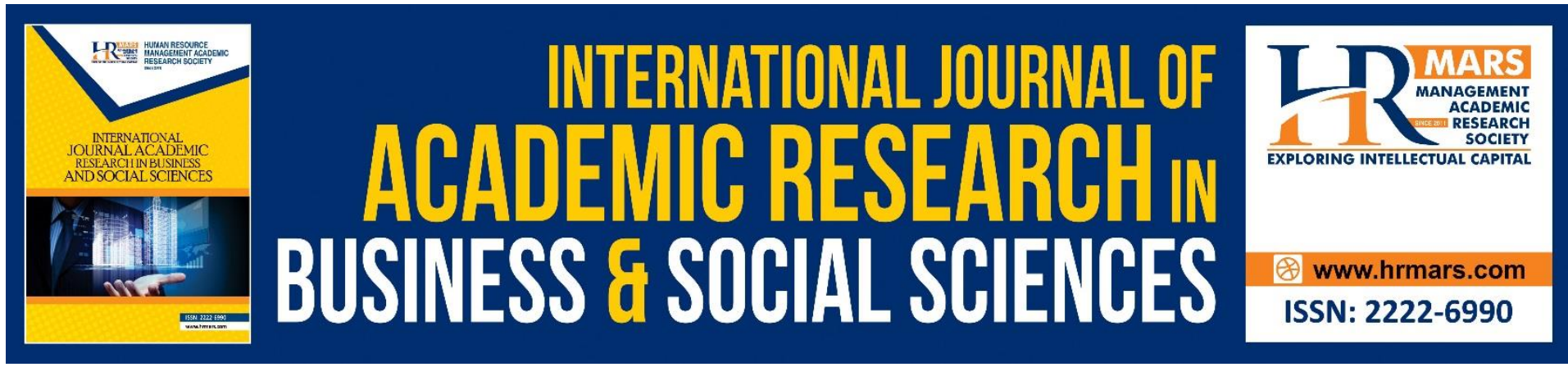

\title{
The Roles of Aesthetics and Information Quality on Continued Use of Digital Library (CUDL) by Malaysian Postgraduate Students
}

\author{
${ }^{1}$ Abd Latif Abdul Rahman \& ${ }^{2}$ Shahruhaida Adayu Mohd Paili \\ ${ }^{1}$ Fakulti Pengurusan Maklumat Universit Teknologi MARA Cawangan Kedah 08400 Merbok, \\ Kedah, ${ }^{2}$ Perpustakaan Negara Malaysia, 232, Jalan Tun Razak \\ 50572 Kuala Lumpur \\ Email: ablatif@uitm.edu.my \& shahruhaida@pnm.gov.my
}

\begin{abstract}
A digital library is a new information system provided by libraries and information centers around the world, including in Malaysia. It is important to study the reasons why and how users accept and use digital libraries. The objective of this study is to investigate the roles of aesthetics where it divided into two types which are classical aesthetics and expressive aesthetics; and information quality on users' continued use of a digital library. The study proposes to investigate the factors that are expected to influence the intention of postgraduate students to continued use of the digital library based on three models: a modified UTAUT2 model, an aesthetics model, and Delone and McLean's Information Success Model. Postgraduate students from University Sains Malaysia (USM) will be selected as the sample to test the research questions and fulfil the research objectives of the study. It is expected that this research will provide new insights into research on continued use of the library (CUDL) in a digital environment.
\end{abstract}

Keywords: Digital Library Continued Use (DLCU), Theories, Constructs

\section{Introduction}

A digital library can be considered as a form of information system which is provided by libraries and information centres throughout the world, including in Malaysia. Many libraries have developed as the main location for users to access library resources or collections. Traditionally libraries have been divided into five types which are: national library, academic library, public library, special library and resource centre. With the advancement of technology and because most students depend on the information sources provided in libraries, libraries have taken the opportunity to build digital libraries to enable their users to gain access to information from the library anywhere and at any time.

Digital libraries were built to manage the bibliographic information of library collections. Technology will continue to bring benefits to libraries and information centers in the future and enable them to enhance the services they provide to their users particularly in this pandemic era (James et al., 2021) and towards future big data era (Lia et al., 2019). 
Many initiatives have been taken in the development of digital libraries around the world, but the development of digital libraries in Malaysia is still in progress. Most of the digital libraries in Malaysia are based in university libraries where, as elsewhere throughout the world, they facilitate undergraduate and postgraduate students to search for information that they need for their academic tasks.

Digital library and physical library is different in terms of the way users use it as well as digital technology. For the digital library, users need to access it by using their digital computer and other media devices with networking, while for the physical library, users only go there to gain information that they need such as books, journals, articles and other documents. A digital library offer ways for users to access digital library collections online. They can therefore obtain the information they need from anywhere and at any time by accessing the digital library at the URL address of the digital library.

Digital libraries support services such as searching, accessing, loaning and downloading. These services are available only from a digital library and not from a traditional library. Users can also make a reservation for items that they wish to borrow, whether the item is available or in circulation at that time. Thus, the digital library provides important benefits to users with no restrictions on making a reservation or any limitation to access, and it also provides rich forms of intellectual works such as audio, video as well as text formats.

It is important that librarians be aware of the aesthetic aspects of the digital library in order to know whether the digital library that has been created by them is suited to the needs of the users. Aesthetics focuses on the interface of the digital library with the users. It consists of classical aesthetics and expressive aesthetics. Good aesthetics can ensure users continue to use the digital library, while poor aesthetics can discourage users. It is necessary for the librarian to understand aesthetics because it involves the elements that are deemed important to design the digital library well so as to create an environment that make it easier for users to use the digital library.

There is a great deal of information provided by a digital library for the user's purposes. Information in the digital library consists of digital information such as information in online databases that subscribed to by the library, digitalized newspaper articles, past examination question papers and so forth. Information provided by the digital library can be considered as trustworthy and up-to-date. Furthermore, most postgraduate students use the information provided by the digital library because of the quantity and quality of the information available. They can search for whatever information that they need in the digital library because most digital libraries provide the information required by their users, especially a university digital library.

Previous research that investigated other information systems has mentioned that aesthetics (Cyr, 2006; Lavie \& Tractinsky, 2004) as well as information quality (Lagzian et al., 2013; Xu \& $\mathrm{Du}, 2021)$ were important factors that can encourage users to continued use of the information source. Using the Extended Unified Theory of Acceptance and Use of Technology (UTAUT2) (Venkatesh et al., 2012), this study set out to investigate the roles of aesthetics and information quality on postgraduate students' intention to continued use of digital library, thus will get them loyalty to use digital library (Xu \& Du, 2021).

\section{Problem Statement of the Study}

A digital library can be considered as a new information system which is developed by many organizations or institutions. There are many libraries in the world especially university libraries, but digital libraries offer new and sophisticated services to the users. Many scholars 
and researchers use the digital library for their academic or research purposes because it can facilitate access to a wide range of valuable information easily and quickly. Users can access the digital library using URL address provided by the university's library, and in this way access the digital library collections for their information needs. There are many collections in the digital library for instance: online databases, electronic journals, electronic books, and inhouse databases. In information system, researchers had done investigate about information quality and aesthetics which it shows that, there are have relationship between them. However, in the digital library environment, both of these important variables have not been proved empirically by the previous researchers. In order to fill the important variables, this research was conducted.

For the aesthetics matter, Van der Heidjen (2003) mentioned that classical and expressive aesthetics have an important role in the decision by a user to use an information system, especially a website. Most users who want to use the website will look first at the interface of the website, and sometimes users are not attracted to the website which does not have good aesthetic values. Lack of awareness of website design issues can cause users to cease using a website (Nadkarni \& Gupta, 2007; Tarafdar \& Zhang, 2008) because based on Gregory et al., (2013) mentioned that aesthetics brings positive effect to the organization in producing the best services to the customers. Theng (1997) pointed out that aesthetics is important in designing a digital library because if there are problems producing a good website in order to overcome the problems on the web, there will also be problems creating a good digital library. He stressed that, creating and designing (aesthetics) a good digital library is important and the influence the aesthetics on the continued use of a digital library needs to be investigated by researchers. Furthermore, Dix (1995) mentioned that if designers feel that they have used the best methodology and model to design a website but have made no effort to test the system, they will not know the users' perception towards the aesthetics of the website and whether the design meets the users' requirements. In Reinecke et al.'s (2013) study, the authors mentioned that users gain their first impression when looking at the website's aesthetics and this will determine whether the users will continue to engage with the site.

It has been noted before by Lavie and Tractinsky (2004); Norman (2004); Sonderegger and Sauer (2010) that both classical and expressive aesthetics can influence whether or not users will use the system and it also can influence the users to buy products offered by the website and continue to use the website. Another important thing that is often ignored by designers is the fact that they can also communicate through aesthetics means (Thorlacius, 2007), and designers should take advantage of this opportunity. It can therefore be assumed that users can easily interact with a website that possesses aesthetic values. Based on the statement that have been made by the previous researcher regarding to the aesthetics, it shows that aesthetics is important to be investigated and there is no researcher who investigate the aesthetics value for the digital library which also can attract users to continued use of digital library and it also can increase the usage of the digital library. This variable is really important because most of the users would like to use information system which can facilitate them to use and pleasing.

Meanwhile, another aspect to be considered is information quality. DeLone and McLean (2003) contended that information quality is also important in the success of an information system, such as a digital library, which deals with information. The variable of quality of information has rarely been included in studies investigating the success of the system and users' intention to continued use of the digital library (Lagzian et al., 2013). It is important to investigate the quality of the digital library, especially its information quality, in order to 
understand users' attitudes towards continued use of the digital library (Cheng, 2014; Chiu et al., 2007). Without quality of the information, the digital library is of little use because most of the users depend on the digital library to provide reliable and accurate information. Besides, poor of the information quality can cause problem to the higher institution (Popoola, et al., 2014) which can give negative effect to the students as well as for the teachers or lecturers.

The most important concern for the success of a digital library is users' acceptance and continued use. However, as Lagzian et al (2013) noted, research on factors affecting users' continuance intention in regard to digital libraries has rarely been conducted. The important thing for the digital library is not only its acceptance but also its continued use (Jeong, 2011); thus it is essential to investigate the factors that may affect users' intention to continued use of digital library (ICUDL). The digital library is only successful if it is accepted and used by users. However, it is necessary to know the reasons for users' acceptance as well as their intentions to continue using the digital library. In other words, the variables that are deemed to have some influence on the continued use of the digital library need to be examined.

In the context of the model used for studying the digital library, some researchers have investigated the acceptance and continued use of digital library. The two main models used by previous researchers are the Technology Acceptance Model developed by Davis (1989) and the Unified Theory of Acceptance and Use of Technology (UTAUT) developed by (Venkatesh et al., 2003).

Previous research, such as that by Thong et al (2002), has investigated the acceptance and continued use of the digital library by examining a set of external variables using the Technology Acceptance Model. Meanwhile, Tibenderana (2010); Orji (2010) and Rahman et al (2011) have attempted to examine the set of variables in Venkatesh's (2003) UTAUT model, with the addition of some other variables relevant to the context of their study.

Thus previous research on digital libraries has focused on the variables which are significant to concerns about acceptance and continued use of the digital library (Alzahrani et al., 2019; Chang et al., 2015; Rosman et al., 2021) as well as on their engagement (Rosman et al., 2021), Affinity (Xu \& Du, 2021), maturity (Sheikhshoaei et al., 2021) as well as the readiness for transformation (Deja et al., 2021). However, there may be other variables that are also significant which have not been examined yet by researchers in the context of the digital library. As can be seen, most previous researchers have used models from the field of information systems or technology to gain answers to their research questions.

To date, important variables such as aesthetics and information quality have not been investigated by previous researchers using the UTAUT2 model developed by Venkatesh et al (2012). Aesthetics and information quality are taken into account to close the gap in previous research in order to better explain the intention to continued use of digital library. In doing so, the understanding of factors influencing the continued use of the digital library would be enhanced.

For this study, the main objectives are to investigate the role of aesthetics and information quality on intention to continued use of a digital library. Even though the digital library may have aesthetic value, librarians also need to take into account the quality of the information, and vice versa. These two elements are of great significance in ensuring users have the intention to continued use of digital library. 


\section{Continued Use of Digital Library (CUDL)}

The term digital library first gained currency in the early 1990s (Agusti, et al., 2016) when universities and institutions began to develop their digital collections. Since then, many researchers have carried out investigations into digital libraries to establish the level of acceptance and continued use of these libraries. The digital library has been investigated by many previous researchers, including researchers in the field of information science, computer science, philosophy, and management science. Many definitions have been constructed by previous researchers in different disciplines and in a variety of situations (Sigh, Mittal \& Ahmad, 2006). Based on Borgman (1999, 2005), the digital library can be defined from two different perspectives: from the technical aspects, as well as from the perspective of the collection, organization and services which can be described by the librarians and information professionals. A digital library can be accessed virtually and the digital library resources are provided to users in a digital form (Rowlands \& Bawden, 1999). The digital library can be accessed via the library's homepage, because the digital library collections include items which are electronic journals and online databases and it can make easier for users to access and obtain the information needed (Hong, 2002). Based on perspective of collection, organization and services, a digital library contains collections of digital objects which are images, texts, and audio and video materials (Witten and Bainbridge, 2012) and manage the information and knowledge to the users (Lynch, 1994). A study of digital libraries is also concerned with the methods of how to access and retrieve material and how to select and share the collections with others. Rahman et al (2011) described the digital library as a library that includes all types of digital collections which users can search, as well as access the resources via the library website for the purposes of viewing, downloading, printing and borrowing. Based on these descriptions and definitions of the digital library, a digital library in this study can be described as a digital library that provides access and ability to search to users through the library's website. An example, when users search the information through the library website with one of the activity either access, downloading or printing with their laptop, personal computer or other media devices, it can be considered as user used the digital library. The digital library contains digital materials which can be accessed by users from anywhere and anytime, because the digital library collections are always available. Therefore, Continued Use of Digital Library (CUDL) is defined as the strength of a respondent's intention to continue using a digital library. It reflects the likelihood that the user would make use of the digital library again in the future. Their Continued use of Digital Library (ICUDL) can be examined through the following dimensions (Venkatesh et al., 2003; Venkatesh et al., 2012; Rahman, et al., 2011).

1. Preference to use the digital library

Digital library become priority to the users in gaining the information that they needed.

2. Expecting in using the digital library

Users have the expectation in using the digital library in the future where they found that the digital library brings benefit to them.

3. Planning to use the digital library in the future

Users have planning in continuing use the digital library and they also plan to use it frequently.

\section{Aesthetics: A Brief Overview}

Aesthetics can be described as "beauty". Various studies have shown the influence of aesthetics on perception of usability; on intention to revisit on trust and credibility (Karvonen, 
2000; Robins \& Holmes, 2008); on usability testing (Sonderegger \& Sauer, 2010); and on fun and enjoyment. Aesthetics has been shown to play an important role in determining the user's use of an information system. The more attractive the system, the more users would like to use it. This shows that aesthetics have a positive influence on users' intentions to continued use of a digital library.

Hartmann et al (2008) revealed that aesthetics can enhance the positive user experience in the context of the World Wide Web (WWW). An experience is important because of it can make the users easier to use the digital library. Besides that, aesthetics also can make the users easy to use the digital library.

Based on the findings of several studies on the subject, it appears that the combination of colours has a significant effect on the perceived attractiveness and aesthetic appeal of a website. Brady and Philips (2003) in their study mentioned that "users found a site with a triadic colour scheme more usable and more aesthetically pleasing than a site with a nonstandard colour scheme", and their findings were supported by Papachristos et al (2011). Colour can also influence the users whether they want to use a particular website or not. However, some designers do not know the suitable colour/s for their website. When the website produces a colour combination, it can attract users to use and view it. For the digital library, the colour combination should match with the purposes of the website. In an article of the design aesthetics leading to loyalty in mobile commerce, investigated by Cyr (2006), he proposed a model for the design aesthetic which was affected by usefulness, ease of use, as well as enjoyment. Van der Heijen (2003) also proposed that perceived attractiveness will influence the usefulness, ease of use as well as enjoyment.

In addition, aesthetics has also been found to enhance the learnability, learning outcomes, and understandability of the message. In the context of the current research, it is assumed that aesthetics can enhance the learnability of the users while using the digital library.

Reinecke et al. (2013) claimed that the user's first impression when looking at the website aesthetics influences whether the user wishes to engage and continue to use it. Alasem (2013) mentioned that lack of awareness of website aesthetics can make the users unaware and can discourage them from continuing to use the site. This is because even though the interface of the webpage is attractive, it is not the only thing users look for; they also look at the content of the webpage. As mentioned before, the content should suit the purpose of the webpage. For instance, the digital library webpage must provide information that can fulfil the user's need.

\section{Classical Aesthetics (CA)}

Classical Aesthetics (CA) is likely to serve as an indication of skilful design. It can be used in a digital library so that the interface of the digital library can be efficient and can attract more users to use it. Here, it is important for the web developer to create an interesting webpage in order to attract the users to continue using the digital library. The image of the system must be reflected in its design in order to fit its purpose.

The purpose of the digital library itself is to provide information to the users, so it must reflect that purpose. In a classical aesthetics, the font style used should be appropriate to the age of the audience; the background texture should also reflect the purpose of the webpage; in addition, the basic search control must work properly with the intuitive aesthetics. So, it can ensure that the characteristics of the classical aesthetics met by the designer of the digital library. It is because; for instance, a digital library must have the basic search that work 
properly so that users can search what information that they needed easily and faster. That's the classical aesthetics work.

According to Lavie and Tractinsky (2004), classical aesthetics satisfies basic human needs, and classical aesthetic considerations are becoming increasingly important in our society. For instance, if the users wish to find specific information, they may choose the digital library as the primary place to find the information. If the website is easy to use, and the information contained in the website is orderly, and the design of the digital library is attractive, users will be influenced to find the information in the digital library website. The classical aesthetics dimension emphasizes orderly and clear design and relates to many design rules advocated by usability experts. Classical aesthetics incorporates adjectives such as clear, clean, pleasant, aesthetic and symmetrical. In the context of the digital library, classical aesthetics is important to ensure that the website of the digital library can be viewed clearly by the users when searching for the information they need. Once the users search for information through the digital library, they can get fast responses due to the classical aesthetics of the digital library This emphasises the important role of the librarians to ensure that the digital library that they implement is suited to the users' needs and, most importantly, that it has the value of classical aesthetics. Besides that, aesthetics also plays an important role in influencing users' use of technologies (Shin, 2012). Users are more drawn to attractiveness, pleasantness (Schenkman \& Jonsson, 2000; Zhang \& Li, 2005) and quality of the website interface (Van Der Heijden, 2003) which can encourage them to continue to use it. There are several studies that have investigated the aesthetics of websites such as (Ivory et al., 2001; Reinecke et al., 2013).

When the website is attractive, clean and clear, it will attract users to use it; in addition, it also can enhance the likelihood of users continuing to use that website. The structure or the arrangement of the content in the website should meet the user's need. The arrangement should be clear and easy to use. This will ensure that users will be attracted to the website and use that website regularly. Therefore, Classical Aesthetics (CA) can be defined as the clean-cut appearance and clarity of the website interface. In other words, Classical Aesthetics (CA) is present when the interface of the digital library is systematic, orderly and the homepage of the digital library is uncluttered. Classical Aesthetics (CA) can be examined by following dimensions (Lavie \& Tractinsky, 2004).

1. Arrangement in the interface

The arrangement of the digital library interface is suited to the users and is easy for the users to use.

2. Clarity

The interface of the digital library is clean as well as clear, and it can facilitate users to use the digital library for their learning.

3. Pleasure in using the digital library

Users of the digital library feel pleasure when they are using the digital library for their learning or when searching the information.

\section{Expressive Aesthetics (EA)}

Another type of aesthetics that is recognised is known as expressive aesthetics, which conveys a sense of creativity and uniqueness (Lavie \& Tractinsky, 2004). Wilson (2015) mentioned that website is important tools for the digital library in order to provide content for the academic libraries. Poor design of the digital library will cause users more difficult to use it. The designers must employ creativity in designing the website and as a result, users are satisfied with the website and in future, they will use it again. 
The principle can be applied to digital libraries as well. The interface of the digital library should be unique in order to ensure that users will be attracted and will continue to use the digital library (Shin, 2012). When the interface is attractive, users can be motivated to use it continuously. Expressive aesthetics of a website has a stronger impact on first time users for their decision process than for repeat users. This means that expressive aesthetics is important for a webpage to capture users and to attract them to decide to continue using the services provided.

Organizational websites, for example, provide the first impression of an organization and have been shown to influence users' decisions about whether to stay on the website or to leave the website and go to the website of another organization. This indicates that expressive aesthetics has an important influence on users' intentions to continued use of a website.

The expressive aesthetics dimension represents designers' creativity, originality, and the ability to break design conventions. Expressive aesthetics is often the only way to make a product stand out. Expressive aesthetics can help an organization promote their products or services. Norman (2004) mentioned that expressive aesthetics can change the emotional state of users visiting the web page. First time users will affected by looking at the expressive aesthetics of the webpage. Designers use their creativity to attract the users to view and, most importantly, to buy or use the services offered. This idea is supported by Zhang and Li (2005) who pointed out that aesthetics is associated with affect, or mood, emotion as well as feeling. It means that expressive aesthetics brings an important element to the users, which can influence whether or not they will continue to use the web page. With increasing use of the Internet, expectations are rising as the number of encounters increases and users gain more experience with a particular website domain. For example, users may have different expectations about the visual design of news websites or online shops.

Expressive aesthetics have been found to play an important role in users' acceptance and usage of the technology. Lavie and Tractinsky (2004) also found that there is high correlation between expressive aesthetics and perceived level of use. As mentioned before, when the design is suited to the purpose of the website, it can facilitate users to use it and users will think that the website is useful for them, and worth their while to continue making use of it. In addition to usefulness, aesthetics has also been found significant for the website.

To increase the number of customers, interface design is increasingly important for a company or organization's website (Venkatesh, 2012). A good interface design (expressive aesthetics) will increase the number of users to view the website. A clear design and good expressive aesthetics will help users to use the digital library's website effectively. Expressive aesthetics can also be used to guide users to discover which page they should go to and where they can find the information that they are looking for.

Therefore, Expressive Aesthetics (EA) can be defined as the originality and creativity of the designer. The digital library is designed by the digital library designers with their original ideas. Expressive Aesthetics (EA) can be examined by the following dimensions (Lavie \& Tractinsky, 2004).

\section{Uniqueness}

The design of the digital library is unique due to the creativity of the designers in designing the digital library website.

\section{Attractiveness}

The design of the digital library can attract users to use the digital library continuously. 


\section{Originality}

The website of the digital library is original, in that the website is designed only for the digital library.

\section{Information Quality: Brief Overview}

A digital library provides many electronic resources that are available for users. Users can search, browse, and retrieve the digital library resources at remote locations at anytime and anywhere, as they wish. According to McLean and DeLone (2003), in order to measure the success of a single system, it is important to measure the quality of the information or the quality of the system. In a digital library, the most important element is information quality, because most of the users rely on the digital library to gain resources as well as to enhance their knowledge. This assertion is supported by Rahman et al. (2011), who found that information quality has a significant impact on decisions to continued use of a digital library. Besides, a library website also must update regularly in order to ensure that information contain in the digital library is up-to -date and it can be easier to the users to use it (Arshad \& Ammen, 2015). If the information is poor, it can make problem to the uses.

While McLean and DeLone (2003) included information quality as a measurement construct for evaluating the success of electronic- commerce, quality of information has rarely been included by researchers investigating the success of the system and the intention to continue using the digital library (Lagzian et al., 2013). One of the reasons listed by the Masrek et al (2009), for why users did not continue using a digital library was low quality of the information quality. It is important, therefore, to investigate the quality of the digital library, especially the information quality in order to know the users' perceptions of whether or not they will continued use of the digital library in the future (Alzahrani,2019 \& Rosman, 2021).

Information quality is deemed important to the users of the digital library, especially for postgraduate students in research fields because they need high quality information to ensure their research is valid and can be a source of reference for others. Information quality is important in order to ensure the correctness, authority, as well as accuracy of the information produced by the researchers. Thus it is not surprising that information quality has been found to strongly influence user satisfaction in the context of an academic library portal (Masrek et al., 2010) and other fields.

The digital librarian should know type of information that is typically used by the users, what information they are searching for and their purpose for seeking the information so that the digital librarians can give the accurate guidance to their users. Each university has its own courses, fields or specialisations that are offered to students. Thus, a digital library needs to take into account what fields are used in the university it serves. If the digital librarian provides unsuitable information that is not really used by the users of the library, it is worthless. Librarians first need to know the courses or fields available in their university. Each researcher, for example, has his or her field of specialization and they need only information that is related to that field.

There is a great deal of information provided by the digital library that is available in different forms. Users can choose which form of information is suitable to their needs. The information that commonly sought by users is that which is available in online databases. Since the digital librarians already know that online databases are frequently searched by users, they need to subscribe to the online databases that are suited to their users.

Therefore, Information Quality (IQ) can be described as the usability of the digital information resources retrieved by the users from the digital library. This Information Quality (IQ) can be 
examined based on the dimensions as below: (derived from DeLone \& McLean, 2003; AlHakim, 2007; Rahman et al., 2011)

1. Relevance

The information in the digital library is related to the field of study of the users.

2. Accuracy

Relates to the correctness, accuracy, as well as freedom from errors in the digital resources provided by the digital library.

3. Comprehensiveness

Relates to the comprehensiveness, completeness and sufficiency of the digital resources provided by the digital library.

4. Authoritativeness

Relates to the reliability and dependability of the digital information in the digital library.

\section{Significance and Benefits of the Study}

As previously mentioned, no published empirical studies have yet investigated the relationship between aesthetics and information quality (IQ) on continued use of the digital library (CUDL) among postgraduate students in Malaysian research university, within the context of the UTAUT2 model (Venkatesh et al., 2012). It is hoped that the findings of this study will provide some useful and significant contributions to the field of digital library through its focus on gaining a better understanding of users' Continued use of Digital Library (CUDL).

From a theoretical perspective, this study will contribute to extending the body of literature pertaining to users' Continued use of Digital Library (CUDL) with the variables considered important to the present study. With the adaption and modification of the Extended Unified Theory of Acceptance and Use of Technology (UTAUT2), developed by the Venkatesh et al. (2012), a new theoretical framework can be developed. Indeed, this is an alternative that could further support and strengthen the existing Extended Unified Theory of Acceptance and Use of Technology (UTAUT2). The added variable for the study are aesthetics (classical expressive and expressive aesthetics) and information quality which can create the new theoretical knowledge to the current body of research concerned with the continued use of digital library. Besides that, the study will help other researcher to look up for other new variables to investigate the continued use of digital library.

From a practical perspective, this study will present the reality of the current situation regarding digital library use, particularly in a research university. Based on the results of the study, librarians will gain a better understanding of the perspective of the users towards the digital library that is provided for them. Without this study, librarians, as well as designers, are not able to know whether the users like the design of the digital library or not and also the information provided to the users are quality and it fulfil the user's need. Besides, academic librarian also will know to support research service where they needed to understand the user information's need (Olmeda-Gómez, 2016).

Other than that, the librarians will also gain better ideas of whether the information that they provide is relevant to their students'/users' requirements or not. If the answer is negative, the librarians could improve the services offered and provide more reliable information to the students. Besides that, librarian can gain more reliable information about users' continued use of the digital library (CUDL). At the end of this thesis, the factors that interact in the users' Continued use of the Digital Library (CUDL) are presented. 
With an understanding of the role of aesthetics and information quality (IQ) on people's continue using a digital library (CUDL), further applications could be developed to personalize the digital library based on aesthetics and information quality. Furthermore, instruments developed in this study can be replicated and tested on other information system domains, such as e-learning. This model also could be utilized as a road map for education and training of digital library professionals in Malaysia; the designers could enhance the design of the digital library, especially with more persuasive and attractive web systems.

\section{Acknowledgement}

Highest gratitude to Malaysian Ministry of Higher Education and Universiti Teknologi MARA (UiTM) (FRGS Research Grant (600-RMI/FRGS/ 5/3 (155/2013) and RAG Research Grant (600RMI/RAGS 5/3 (143/2013) for giving us opportunity and ample time in doing research.

\section{Corresponding Author}

Abd Latif Abdul Rahman

Faculty of Information Management Universiti Teknologi MARA Kedah 08400 Merbok

Kedah, Malaysia

Email: ablatif@uitm.edu.my

\section{References}

Alasem, A. N. (2013). Evaluating the usability of Saudi digital library's interface (SDL). In Proceedings of the World Congress on Engineering and Computer Science (Vol. 1)

Al- Hakim, Latif. (2007). Information quality factors affecting innovation process. International Journal of Information Quality, 1 (2), 162- 176

Alzahrani, A. I., Mahmus, I., Ramayah, T., Alfarraj, O., Alalwan, O., \& Alalwan, N. (2019). Modelling digital library success using the DeLone and McLean information system success model, 51 (2), 291-306

Arshad, A., \& Ameen, K. (2015). Usage patterns of Punjab University library website: a transactional log analysis study. The Electronic Library, 33 (1), 65 - 74.

Agosti, M., Ferro, N., \& Silvello, G. (2016). Digital library interoperability at high level of abstraction. Future Generation Computer Systems, 55, 129-146.

Borgman, C. (1999). What are the digital libraries? Competing vision. Information Processing and Management, 35, 227-243

Borgman, C. L., Smart, L. J., Millwood, K. A., Finley, J. R., Champeny, L., Gilliland, A. J., \& Leazer, G. H. (2005). Comparing faculty information seeking in teaching and research: Implications for the design of digital libraries. Journal of the American Society for Information Science and Technology, 56(6), 636-657.

Brady, L., \& Phillips, C. (2003). Aesthetics and usability: A look at color and balance. Usability News, 5(1), 1-4.

Chang, S. S., Lou, S. J., Cheng, S. R., \& Lin, C. L. (2015). Exploration of usage behavioral model construction for university library electronic resources, The Electronic Library, 33(2), 292-307. https://doi.org/10.1108/EL-10-2013-0195

Chang, J. F., Chen, J. F., Kao, C. W., \& Huang, Y. M. (2016). Integrating ISSM into TAM to enhance digital library services: a case study of the Taiwan Digital Meta-Library. The Electronic Library, 34(1), 58-63

Cheng, Y. C. L. M. H. (2014). Effect of website aesthetics on approach intention. Retrieved April, 25, 2015. 
Cheng, Y. M. (2014). Why do users intend to continue using the digital library? An integrated perspective. Aslib Journal of Information Management, 66(6), 640-662.

Chiu, C. M., Sun, S. Y., Sun, P. C., \& Ju, T. L. (2007). An empirical analysis of the antecedents of web-based learning continuance. Computers \& Education, 49(4), 1224-1245.

Cyr, D., Head, M., \& Ivanov, A. (2006). Design aesthetics leading to m-loyalty in mobile commerce. Information \& Management, 43(8), 950-963.

Davis, F. D. (1989). Perceived usefulness, perceived ease of use, and user acceptance of information technology. MIS quarterly, 319-340.

Deja, M., Rak, D., Bell, B. (2021) Digital transformation readiness: perspectives on academia and library outcomes in information literacy, The Journal of Academic Librarianship, 47, $1-15$

Delone, W. H., \& McLean, E. R. (2003). The DeLone and McLean model of information systems success: a ten-year update. Journal of Management Information Systems, 19(4), 9-30.

Dix, A. (1995). Cooperation without (reliable) communication: Interfaces for mobile applications. Distributed Systems Engineering, 2(3), 171.

Gregory, C. K., Meade, A. W., \& Thompson, L. F. (2013). Understanding internet recruitment via signaling theory and the elaboration likelihood model. Computers in Human Behavior, 29(5), 1949-1959.

Hartmann, J., Sutcliffe, A., \& De Angeli, A. (2007). Investigating attractiveness in web user interfaces. In Proceedings of the SIGCHI Conference on Human Factors in Computing Systems (pp. 387-396). ACM.

Hong, W., Thong, J. Y., \& Wai-Man Wong, K. Y. T. (2002). Determinants of user acceptance of digital libraries: an empirical examination of individual differences and system characteristics. Journal of Management Information Systems, 18(3), 97-124.

James, M., Carla, L., Christina, M., Marc, S. (2021) Expanding digital academic library and archive services at the University of Calgary in response to the COVID-19 pandemic, International Federation of Library Associations and Institutions, 1-16

Jeong, H. (2011). An investigation of user perceptions and behavioral intentions towards the e-library. Library Collections, Acquisitions, and Technical Services, 35(2), 45-60.

Ivory, M. Y., Sinha, R. R., \& Hearst, M. A. (2001). Empirically validated web page design metrics. In Proceedings of the SIGCHI Conference on Human Factors In Computing Systems (pp. 53-60)

Karvonen, K. (2000). The beauty of simplicity. In Proceedings on the 2000 Conference on Universal Usability (pp. 85-90). ACM.

Lagzian, F., Abrizah, A., \& Wee, C. M. (2013). An identification of a model for digital library critical success factors. The Electronic Library, 31(1), 5-23.

Lavie, T., \& Tractinsky, N. (2004). Assessing dimensions of perceived visual aesthetics of web sites. International Journal of Human-Computer Studies, 60(3), 269-298.

Lia, S., Jiaoa, F., Zhanga, Y., Xub, X. (2019) Problems and Changes in Digital Libraries in the Age of Big Data From the Perspective of User Services, The Journal of Academic Librarianship, 22-30

Lynch, C. A. (1994). The integrity of digital information: Mechanism and definitional issues. Silver Spring, MD: ASIS.

Nadkarni, S., \& Gupta, R. (2007). A task-based model of perceived website complexity. MIS Quarterly, 501-524.

Norman, D. A. (2004). Emotional design: Why we love (or hate) everyday things. Basic Books, New York. 
Olmeda-Gómez, C., \& de Moya-Anegón, F. (2016). Publishing trends in library and information sciences across european countries and institutions. The Journal of Academic Librarianship, 42(1), 27-37.

Orji, R. O. (2010). Impact of gender and nationality on acceptance of a digital library: an empirical validation of nationality based UTAUT using SEM. Journal of Emerging Trends in Computing and Information Sciences, 1(2), 68-79.

Papachristos, E., \& Avouris, N. (2011). Are first impressions about websites only related to visual appeal?. In Human-Computer Interaction-INTERACT 2011 (pp. 489-496). Springer Berlin Heidelberg.

Popoola, B. A., Chinomona, R., \& Chinomona, E. (2014). The influence of information quality, system quality and service quality on student's self-efficacy at institutions of higher learning in South Africa. Mediterranean Journal of Social Sciences, 5(27 P2), 974.

Rahman A. L. A., Jamaludin, A., Mahmud, Z. (2011). Intention to use digital library based on modified UTAUT model: Perspectives of Malaysian postgraduate students, International Journal of Information and Communication Engineering, 5(3)

Reinecke, K., Yeh, T., Miratrix, L., Mardiko, R., Zhao, Y., Liu, J., \& Gajos, K. Z. (2013, April). Predicting users' first impressions of website aesthetics with a quantification of perceived visual complexity and colorfulness. In Proceedings of the SIGCHI Conference on Human Factors in Computing Systems (pp. 2049-2058). ACM.

Robins, D., \& Holmes, J. (2008). Aesthetics and credibility in web site design.Information Processing \& Management, 44(1), 386-399.

Rowlands, I., \& Bawden, D. (1999). Building the digital library on solid research foundations. Aslib Proceedings, 51 (8), 275-282

Schenkmn, B., \& Jonsson, F. (2000). Aesthetics and preferences of web pages. Behaviour and Information Technology, 19 (5), 367-377

Sheikhshoaei, F., Naghshineh, N., Alidousti, S., Nakhoda, M., Dehdarirad, H. (2021) Development and validation of a measuring instrument for digital library maturity, Library and Information Science Research, 43, 1-6

Shin, D. H. (2012). Cross-analysis of usability and aesthetic in smart devices: what influences users' references? Cross Cultural Management, 19 (4), 563-587

Sonderegger, A., \& Sauer, J. (2010). The influence of design aesthetics in usability testing: Effects on user performance and perceived usability. Applied Ergonomics 41, 403-410

Singh, G., Mittal, R., \& Ahmad, M. (2006). A bibliometric study of literature on digital libraries. The Electronic Library, 25 (3), 342- 348

Tarafdar, M., \& Zhang, J. (2008). Determinants of reach and loyalty-a study of Website performance and implications for Website design. Journal of Computer Information Systems, 48(2), 16.

Theng, Y. L. (1997). Addressing the" lost in hyperspace" problem in hypertext(Doctoral dissertation, Middlesex University).

Thong, J. Y., Hong, W., \& Tam, K. Y. (2002). Understanding user acceptance of digital libraries: what are the roles of interface characteristics, organizational context, and individual differences?. International journal of human-computer studies, 57(3), 215-242.

Thorlacius, L. (2007). The role of aesthetics in web design. Nordicom Review,28(1), 63-76.

Tibenderana, P., Ogao, P., Ikoja-Odongo, J., \& Wokadala, J. (2010). Measuring levels of endusers' acceptance and use of hybrid library services. International Journal of Education and Development using ICT, 6(2), 33-54. 
Van der Heijden, H. (2003). Factors influencing the usage of websites: the case of a generic portal in The Netherlands. Information \& management, 40(6), 541-549.

Venkatesh, V., Thong, J. Y., \& Xu, X. (2012). Consumer acceptance and use of information technology: extending the unified theory of acceptance and use of technology. MIS quarterly, 36(1), 157-178.

Wilson, D. E. (2015). Web content and design trends of Alabama academic libraries. The Electronic Library, 33 (1), 88 - 102

Witten, I., \& Bainbridge, D. (2002). How to build a digital library. Morgan Kaufmann.

Venkatesh, V., Thong, J. Y., \& Xu, X. (2012). Consumer acceptance and use of information technology: extending the unified theory of acceptance and use of technology. MIS quarterly, 36(1), 157-178.

Xu. F., \& Du, J. T. (2019) Examining differences and similarities between graduate and undergraduate students' user satisfaction with digital libraries, The Journal of Academic Librarianship, 45, 1-9

Zhang, P., \& Li, N. (2005). The importance of affective quality. Communications of the ACM, 48(9), 105-108. 